\title{
A Short History of Primary Care Practice-based Research Networks: From Concept to Essential Research Laboratories
}

\author{
Larry A. Green, MD and John Hickner, MD, MSc
}

Sail forth-steer for the deep waters only, reckless $O$ Soul, exploring, I with thee, and thou with me, for we are bound where mariner has not yet dared to go, and we will risk the ship, ourselves and all.

This is a story about the evolution of practice-based research networks (PBRNs) in the United States. It is largely a story about family physicians, but it includes important work by clinicians in other disciplines, especially pediatrics. As with all histories, the viewpoint is that of the authors, who have not been dispassionate observers. Larry Green has been a prime mover of these events from the beginning. John Hickner came on the PBRN scene at the 1983 North American Primary Care Research Group meeting in Banff, Canada, where he decided he "wanted to be just like those Ambulatory Sentinel Practice Network (ASPN) guys." This synopsis does not adequately capture the enthusiasm, energy, professional risk, volunteerism, and devotion of the many academic and community physicians, researchers, office staffs, and patients who have worked together to improve and transform primary care by carefully observing and interpreting the phenomenon of primary care practice as it unfolds each day. We have included references that contain

Submitted 2 August 2005; revised 9 November 2005; accepted 9 November 2005.

From the Department of Family Medicine, University of Colorado Health Sciences Center, Denver, CO (LAG); The Robert Graham Center, Washington, DC (LAG); Department of Family Medicine, University of Chicago Pritzker School of Medicine, Chicago, IL (JH).

Conflict of interest: none declared.

Corresponding author: John Hickner, MD, MSc, Department of Family Medicine, University of Chicago Pritzker School of Medicine, 5841 S. Maryland Avenue, MC7110, Suite M156, Chicago, IL 61637-1470 (E-mail: jhickner@uchicago.edu). bits of PBRN history and lore for those who wish to know more about what the Institute of Medicine called "the most promising infrastructure development that [the committee] could find to support better science in primary care." ${ }^{1}$ This article incorporates information previously published in a monograph by the American Academy of Family Physicians. $^{2}$

\section{Pioneers of Practice-based Research}

Before there were research institutes or networks of practices, there were individual practitioners who studied their patients' problems with scientific rigor. Among these were 5 general practitioners who have been recognized for their seminal work during the past 125 years. They are James Mackenzie, Will Pickles, John Fry, F. J. A. Huygen, and Curtis G. Hames. Each of these pioneers demonstrated that important new knowledge can be discovered by practicing family physicians. These doctors all wondered about their patients' problems, and they developed a systematic means of gathering, recording, and aggregating data on their patients.

James Mackenzie attended medical school in Edinburgh in the late 1800s and practiced in Burnley, England. He wrote, "I had not been long in the practice when I discovered how defective was my knowledge. I left college under the impression that every patient's condition could be diagnosed. For some years I thought that this inability to diagnose my patients' complaints was due to personal defects. But gradually, through consultations and other ways, I came to recognize that the kind of information I wanted did not exist." ${ }^{3}$ Mackenzie was a general practitioner who had a special interest in heart disease. He thirsted for better knowledge and displayed critical attention to clinical details and was an astute observer. He was knighted for his work, and Sir James Mackenzie demonstrated the 
power of practice-based research before this century began.

Will Pickles served his patients in the town of Wensleydale, England for 50 years, and it was from this practice that he conducted detailed epidemiologic research over some 30 years in the mid 20th century. His book Epidemiology in Country Practice describes various epidemic illnesses, such as infectious hepatitis and epidemic pleuritis.

Anyone claiming that there is not important research to be done in primary care practice need only review Will Pickles' work ${ }^{4}$ to realize his or her error.

John Fry studied his patients as he saw them. In action at his office in Beckenham, England during the summer of 1991, as his patients came and visited with him, he first listened carefully without being diverted. Then he made notes in a notebook about this visit, collecting elements he had selected to record as the consultation continued. In only a few minutes, the patient's concern was addressed and Fry's "minimum data set" had been collected. Because of this meticulous reporting, he was able to declare what was contained in his practice, author clinical texts, and calculate rates of illnesses, diseases and services-tasks that are not often achieved by even the most computerized family physician today. He demonstrated "the tremendous scope and opportunities that family physicians (general practitioners) have to observe, study, analyze, and research their patients and the problems and the diseases from which they suffer."

F. J. A. Huygen focused with painstaking detail on recording the complexities of family life and health in his practice. He was the sole general practitioner in an area of The Netherlands that had little migration. His book, Family Medicine: The Medical Life History of Families, ${ }^{6}$ reveals a multigenerational biopsychosocial understanding of persons within their families. He used the case history method to characterize families (eg, young family, older family, family with a father who has a chronic illness, family with a disabled child).

Curtis G. Hames had an irrepressible curiosity during his lifelong practice in rural Claxton, GA. His work culminated in the famous Evans County Cardiovascular Studies. In 1971, Curtis wrote that the studies were developed "... from the clinical observation that coronary heart disease appeared to occur less frequently among blacks than whites, even though hypertension was obviously more common in blacks and they consumed a higher animal fat diet." 7 He elegantly detailed his study site, noting, for example, that there were 2174 households, including 324 one-person households; and for those 14 years of age or older in Evans County, 3300 were married, 486 widowed, 129 divorced, and 1199 never married. He described the terrain as composed of red clay or sandy soil, covered by pine forests harvested for pulpwood, turpentine, and lumber. Hames united classical epidemiology and family medicine in what he called "the total approach" to understanding the basis of health and disease. His academic collaborator, John Cassel, credited the excellent rapport between Dr. Hames and the population of Evans County for their astonishing $92 \%$ success rate in a study designed to include every adult resident in the county over the age of 40 .

Each of these research pioneers provided inspiration for the development of practice-based, primary care research networks because each demonstrated that important new knowledge, not otherwise accessible, could be discovered by the practicing family physician.

\section{The International Scene, 1950s through 1970s}

At the 1979 meeting of the North American Primary Care Research Group (NAPCRG), after Gene Farley proposed a national sentinel practice research network, a steering committee was formed to consider the idea. Amid other preliminary work, the committee members made contact with individuals and organizations around the globe in search of existing "networks" that actively involved general and family practitioners. They discovered a surprising level of collaborative work around the globe. Whereas the World Health Organization regularly operated community-based investigations about particular diseases in various countries, some examples were found that were explicitly based in family and general practice.

In Birmingham, England, 14,500 patients were monitored for contacts with their general practitioners via a computer-based weekly batching system overseen by K. W. Cross. J. A. Baldwin conducted the Oxford Record Linkage Study, which was partially described in the 1974 Royal Society of Health monograph, Community Health Information Systems. He suggested that medicine needed new systems of 
information to know the behavior of health care systems and to gather extensive information about the populations served. He pointed out that information systems based in primary care were technologically and economically feasible and held sufficient promise to warrant their development. The Record Linkage Study developed ways of acquiring data as a by-product of basic clinical operations.

Charles Bridges-Webb recalled the 1962 to 1963 Australian National Morbidity Survey based on 85 volunteer general practitioners throughout Australia, and he reported a pharmaceutical company-sponsored, 6-year reporting exercise by 50 full-time general practitioner-recorders and many other part-time recorders. Over one million contacts were recorded using a triplicate prescription as the basic means of reporting. The Canadian Influenza and Surveillance System had demonstrated that family doctors could generate reliable and useful nationwide data on a health problem of public concern. ${ }^{8}$ This project led directly to the formation of the Canadian National Recording System (NaReS), the PBRN of the College of Family Physicians of Canada.

The Sentinel Stations of The Netherlands began reporting in 1970 and traced its roots to the late 1960s, when the first department of general practice was established at Utrecht. The Dutch government provided a permanent grant to establish The Netherlands Institute for General Practice in 1965 and encouraged a group of pioneers to start a set of cooperative studies about general practice. The new institute created a national network of sentinel general practices to gain insight into the morbidity patterns of the Dutch population. The structure of the health system permitted stratification of the practices to include $1 \%$ of the population and to be representative of the entire population of The Netherlands in age, sex, and urbanization. The practices used a paper data collection form called the "weekly return" that permitted a variety of problems to be monitored and studied, with changes in topics occurring annually. In addition to the regular weekly reporting, the Sentinel Stations conducted longitudinal studies among patients with particular disorders. By1979, the Sentinel Stations had reported on 30 issues as varied as attempted suicide, skull trauma in traffic, suspicion of a battered child, and prescriptions for the morning-after pill. The Dutch system blended surveillance and research and provided convincing evidence of the feasibility of PBRNs.

\section{Early Efforts in the United States}

Despite these exciting developments in other countries, the prevalent academic view in the United States during this time period was that primary care practices were relatively boring places that might be potential sites for the application of the fruits of research done elsewhere in research laboratories, hospitals, and institutes. It was not until public demand for the rebirth of general practice as family medicine in the late1960s that an alternative viewpoint emerged in the United States. Once the new specialty of family medicine and its training programs were launched in 1969, innovative primary care leaders proposed classification systems to describe the work of family physicians and other primary care clinicians. ${ }^{9-16}$ Systematic descriptions of family medicine ${ }^{17}$ and primary care ${ }^{18}$ were established based on data developed and shared among practices. These early descriptions illuminated the content and complexity of the work occurring at medicine's frontlines and stimulated the fledgling primary care academic community to experiment with data collection systems.

Specific studies, eg, assessment of prophylaxis treatment for acute otitis media by pediatricians, ${ }^{19}$ demonstrated that important research could be done in community practices. These developments inspired the first regional PBRNs. Two regional networks started in the 1970s: the Family Medicine Information System in Colorado (FMIS) and the Cooperative Information Project (COOP). ${ }^{20-22}$ These 2 networks learned from each other and succeeded in conducting and publishing studies focused on what was happening in primary care. They attracted funding from medical schools, national philanthropic foundations, and federal programs such as Health for Underserved Rural Areas, and demonstrated "proof of concept" in the United States.

\section{Expanding across the Continent: The ASPN}

The NAPCRG Sentinel Practice Steering Committee, which included Lorne Becker, Larry Culpepper, Eugene Farley, Jack Froom, Rick Kirkwood, Jack Medalie, Walter Rosser, Alan Shapiro, Kerr White, Maurice Wood, David Yens, and Larry Green, formed several working committees 
and recruited other members of NAPCRG to examine the critical issues that required resolution before proceeding with implementation. These volunteer subcommittees had input from some 60 persons as they conducted their work from their own offices and prepared written reports addressing key questions. What are the questions that justify the creation of a sentinel practice network? What are the validity and reliability issues? What are the privacy, security, and confidentiality issues? What denominators are required for a US network? Why would practitioners want to be part of a sentinel practice network, and what will they need to participate for long periods of time? At the NAPCRG meeting in Lancaster, PA (16 April 1980), the steering committee reported its work and recommended that NAPCRG support the development of a North American sentinel practice network. The membership endorsed this recommendation and approved an initial budget of approximately $\$ 1200$.

After reviewing progress to date in 1981, Kerr White, then vice president of the Rockefeller Foundation, approved the first of 3 annual Foundation grants-in-aid of $\$ 25,000$ to begin the Ambulatory Sentinel Practice Project of North America (ASPPN). This funding permitted further planning meetings to design studies, set up a coordinating center and to recruit Linda Niebauer, the first staff member for the network-who later became known as "the mother of PBRNs in the United States." The name ASPPN was subsequently shortened to Ambulatory Sentinel Practice Network (ASPN) in 1983 at the suggestion of Milt Seifert, an innovative Minnesota family physician and ASPN board member, who noted that the idea was not a one-time project, but an enduring infrastructure. As of 1 November 1981, a steering committee was impaneled composed of Lorne Becker, Gene Farley, Bill Freeman, Jack Froom, Curtis Hames, Walt Rosser, Milton Seifert, Maurice Wood, and Larry Green. This steering committee decided that the new network's first studies would concern headache, pelvic inflammatory disease, and miscarriage. Pocket-sized data forms, "cards," were used effectively by the ASPN physicians for these and other studies (Figure 1). After piloting the studies, data collection began in November 1982 in 38 practices in the United States and Canada. These 3 descriptive studies changed the way physicians approach these common problems ${ }^{23-26}$ and removed doubt that important research could be accomplished. Weekly practice data reports and "card" studies confirmed the ability of a group of volunteer primary care clinicians to sustain their research efforts as a network for an extended period of time, addressing a variety of relevant questions. Figure 1 is an example of a typical ASPN card.

In 1984, a pivotal event for ASPN occurred that became known as the Peaceful Valley Massacre. In Peaceful Valley, CO at the first ASPN Convocation, a recurring meeting of the practices, the steering committee, investigators, and leaders from various interested organizations, 3 experienced researchers proposed a study of chest pain to the practitioners, who proceeded to demolish the proposal, preferring other approaches, and topics. This event was a bit painful but established a fundamental principle that has served ASPN and other networks well ever since. The practices are in charge.

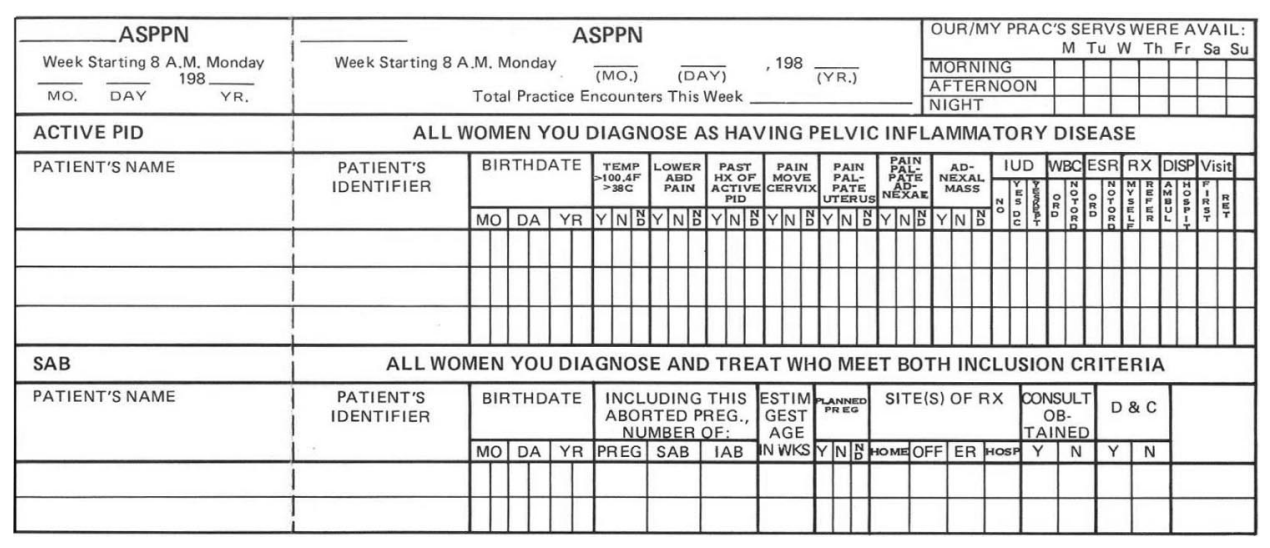

Figure 1. Example of an ASPN data card for reporting cases. 


\section{Moving On}

In 1984, the American Academy of Pediatrics (AAP), prompted by the leadership of Robert Haggerty, Evan Charney, and Barbara Starfield, decided to explore creating another national PBRN, organized around the AAP's state chapter system. This network developed collaboratively with ASPN and was named Pediatric Research in Office Settings (PROS). It launched in 1986 and demonstrated that another important national network was feasible. It continues to operate under the direction of its founding director, Mort Wasserman, as a program of the AAP focused on the clinical problems and health care of children.

In 1985, Jack Froom and Larry Culpepper initiated the International Primary Care Network (IPCN), ${ }^{27}$ which emulated the policies and procedures of ASPN. IPCN conducted its first study involving 9 countries, discovering significant international variation in the treatment of acute otitis media. ${ }^{28}$ Family physicians and primary care clinicians the world over took note of the potential of practice-based research, and other nations established their own networks.

Table 1. ASPN Performance Characteristics, 1983 to 1990 (as of September 1 each year)

\begin{tabular}{|c|c|c|c|c|c|c|c|c|}
\hline & 1983 & 1984 & 1985 & 1986 & 1987 & 1988 & 1989 & 1990 \\
\hline $\begin{array}{c}\text { Number of } \\
\text { practices }\end{array}$ & 38 & 46 & 47 & 52 & 64 & 71 & 76 & 75 \\
\hline Percent rural & $63 \%$ & $63 \%$ & $65 \%$ & $60 \%$ & $62 \%$ & $59 \%$ & $59 \%$ & $53 \%$ \\
\hline $\begin{array}{l}\text { Number of } \\
\text { clinicians }\end{array}$ & 78 & 138 & 145 & 183 & 190 & 216 & 213 & 314 \\
\hline Mean age & 38 & 37 & 40 & 39 & 38 & 39 & 38 & 39 \\
\hline $\begin{array}{l}\text { Number of } \\
\text { doctors }\end{array}$ & 66 & 117 & 125 & 158 & 167 & 188 & 182 & 264 \\
\hline $\begin{array}{r}\text { Number of } \\
\text { residents }\end{array}$ & 0 & 0 & 0 & 0 & 0 & 0 & 15 & 94 \\
\hline \multicolumn{9}{|c|}{ Availability of practices' doctors to respond to patients } \\
\hline Least & $\begin{array}{l}63 \% \text { (Sunday } \\
\text { afternoon) }\end{array}$ & $\begin{array}{r}69 \% \text { (Sunday } \\
\text { afternoon) }\end{array}$ & $\begin{array}{l}65 \% \text { (Sat } \\
\text { evening) }\end{array}$ & $65 \%$ (Sat eve.) & $\begin{array}{r}68 \% \text { (Sunday } \\
\text { afternoon) }\end{array}$ & $\begin{array}{l}70 \% \text { (Sun } \\
\text { evening) }\end{array}$ & $\begin{array}{l}70 \% \text { (Sunday } \\
\text { afternoon) }\end{array}$ & $\begin{array}{r}72 \% \text { (Sunday } \\
\text { afternoon) }\end{array}$ \\
\hline Most & $\begin{array}{l}\text { 98\% (Monday } \\
\text { afternoon) }\end{array}$ & $\begin{array}{l}96 \% \text { (Tuesday } \\
\text { afternoon) }\end{array}$ & $\begin{array}{l}\text { 94\% (Tuesday } \\
\text { afternoon) }\end{array}$ & $\begin{array}{l}98 \% \text { (Tuesday } \\
\text { afternoon) }\end{array}$ & $\begin{array}{c}\text { 95\% (Tuesday } \\
\text { morning) }\end{array}$ & $\begin{array}{c}97 \% \text { (Tuesday } \\
\text { morning) }\end{array}$ & $\begin{array}{c}96 \% \text { (Tuesday } \\
\text { morning) }\end{array}$ & $\begin{array}{r}98 \% \text { (Friday } \\
\text { morning) }\end{array}$ \\
\hline Evenings & $70 \%$ to $75 \%$ & $70 \%$ to $78 \%$ & $64 \%$ to $72 \%$ & $65 \%$ to $76 \%$ & $69 \%$ to $76 \%$ & $70 \%$ to $82 \%$ & $70 \%$ to $85 \%$ & $72 \%$ to $86 \%$ \\
\hline $\begin{array}{l}\text { Coverage by } \\
\text { practice } 52 \\
\text { weeks a year }\end{array}$ & $69 \%$ & $70 \%$ & $70 \%$ & $78 \%$ & $77 \%$ & $76 \%$ & $76 \%$ & $80 \%$ \\
\hline Reporting rate & & $89 \%$ & $86 \%$ to $93 \%$ & $93 \%$ to $95 \%$ & $95 \%$ to $98 \%$ & $89 \%$ to $97 \%$ & $94 \%$ & $92 \%$ \\
\hline \multicolumn{9}{|l|}{$\begin{array}{l}\text { Age/sex } \\
\text { reports* }\end{array}$} \\
\hline $\begin{array}{l}\text { Number } \\
\text { submitted } \\
\text { by year's } \\
\text { end }\end{array}$ & 30 & 31 & 41 & 38 & 54 & 61 & 46 & 67 \\
\hline $\begin{array}{l}\text { Number } \\
\text { completely } \\
\text { enumerated }\end{array}$ & d & 11 & 21 & 30 & 48 & 49 & 44 & 63 \\
\hline $\begin{array}{l}\text { Total } \\
\text { patients }\end{array}$ & 114,889 & 106,402 & 200,686 & 166,509 & 222,430 & 266,198 & 297,923 & 309,925 \\
\hline $\begin{array}{l}\text { Percent } \\
\text { female }\end{array}$ & $56 \%$ & $55 \%$ & $57 \%$ & $57 \%$ & $56 \%$ & $56 \%$ & $56 \%$ & $56 \%$ \\
\hline $\begin{array}{l}\text { Estimated } \\
\text { active } \\
\text { population }\end{array}$ & 145,529 & 157,882 & 230,056 & 227,857 & 263,620 & 309,838 & 327,013 & 346,933 \\
\hline $\begin{array}{l}\text { Average } \\
\text { encounters } \\
\text { per practice } \\
\text { each week }\end{array}$ & 160 & 167 & 156 & 177 & 191 & 195 & 184 & 195 \\
\hline
\end{tabular}

*Age/sex registers are reported for the previous 2-year period (e.g., 1982 to 83 age/sex registers are collected in 1984). 
In 1986, ASPN became a formal legal entity, a corporation with a board of directors with majority representation by practicing physicians. Table 1 shows critical performance characteristics of ASPN from its beginning through 1991, confirming the ability of a group of volunteer primary care clinicians to sustain their research efforts as a network for an extended period of time, rigorously addressing a variety of relevant questions.

In the 1990s, ASPN matured as a research organization with a national and international reputation. Under the leadership of Paul Nutting, ASPN was productive during these years, publishing more than 50 manuscripts. ASPN outgrew its revenues in 1999 and discontinued operating as an independent corporation. It was reborn as the American Academy of Family Physicians' National Network for Family Practice and Primary Care Research, subsequently shortened to the AAFP National Research Network (NRN). NRN now functions as a program of the AAFP, similar to PROS and the AAP.

\section{Other National Networks}

As ASPN and other regional networks matured in the 1980s, other organizations explored practicebased research. For example, The American College of Physicians (ACP) collaborated in a study of the COOP functional charts; their interest rekindled in 1999 with the establishment of a quality improvement group, which transformed into ACPNet in 2002. The American Board of Family Medicine, in cooperation with Health Learning Systems Inc. (Lyndhurst, NJ), launched in 1987 a national network of diplomates named The Clinical Experience Network. Their first study focused on managing hypertension in family practice. It took a real-world approach and specifically sought information about quality of life and cost/benefit measures. The study was overseen by an independent editorial board and 20 regional survey coordinators.

The Practice Partner Research Network (PPRNet) also took a national scope. This network, composed of practices using the same electronic medical record, included some 57 practices by the mid-1990s. Each month the practices extract data from their records using a program designed to collect information regarding patient-specific reasons for visits, diagnoses, medications, laboratory and radiology tests, and some outside records such as consultation reports. These are linked to a patient-specific code in the central database that cannot be linked to individual patients or providers, but permits investigation of questions across the entire system. PPRNet, led by Steve Ornstein, has been very successful in securing national grant funding focusing their work on practice improvement. ${ }^{29,30}$

\section{More Regional Networks}

In 1994, the Fournal of Family Practice published a special issue on practice-based research. A survey indicated the existence of 28 active networks in North America. Most were regional in scope, and among them were regional networks launched in the 1980s that exemplified the work of these networks. ${ }^{31,32}$ For example, the Pediatric Practice Research Group was established in 1984, affiliated with Children's Memorial Hospital (Chicago, IL), focused on the epidemiology, natural history, and diagnosis of common ambulatory pediatric problems. Its attention to rigor and successful publication of its results provided another positive example of the value of primary care PBRNS.

The Wisconsin Research Network (WReN), established in 1987, demonstrated the synergy that could be attained through cooperation of the Wisconsin Academy of Family Physicians and the University of Wisconsin Department of Family Medicine. Its tenacity and advocacy for engagement of the American Academy of Family Physicians in network development provided another locus of leadership that benefited all other networks.

The Upper Peninsula Research Network (UPRNet), established in 1988, was affiliated with Michigan State University and adopted dual objectives of research and research training. It had a rural focus, and its leadership overlapped with the ASPN board, providing opportunities to better understand the type of work that needs a national network rather than a local network.

The Research Association of Practicing Physicians (RAPP) in Ohio lead by Kurt Stange conducted the direct observation of primary care study, which was the basis of an entire issue of the fournal of Family Practice in 1998. These and other regional networks provided further evidence of primary care clinicians interest in and the feasibility and importance of networks as a key infrastructure for family medicine and primary care research. 


\section{The Federation of PBRNs}

By the mid-1990s, a growing number of regional PBRNS had become experienced research organizations. To develop synergy among these regional networks and with the ASPN, directors of these promising regional networks attended the annual ASPN convocation to explore areas of collaboration and to learn from each other's experiences. These ASPN associates included WReN (John Beasley), NEON (Valerie Gilchrist), COOP (John Wasson), OKPRN (Jim Mold), UCSFNet (Mary Croughan), STARNET (Walt Calmbach), UPRNet (John Hickner), RAPP (Kurt Stange), (MAFPRN) Kevin Peterson, NYMetNet and FPRN (John Ryan), Nebraska Research Network (Ben Crabtree), and Western New York Rural Health Research Network (Paul James). In 1997 this informal group, led by John Hickner and John Beasley, agreed to formalize their relationship with each other and established the Federation of PBRNs, which became known as the "Federation." The 3 goals of the Federation are advocacy for practicebased research, building capacity for practice-based research, and fostering collaboration and communication among networks. Although most networks are predominately family medicine, the Federation welcomes all primary care PBRNs and now includes pediatric, internal medicine, and nursing networks. In 2000, the secretariat for the FPBRN was moved from the University of Wisconsin to the American Academy of Family Physicians, where it remains today. More information about the FPBRN, which now has 58 network members and affiliates is available at http://www.aafp.org/ $\mathrm{x} 19545 . \mathrm{xml}$.

\section{Financing PBRNs}

The PBRNs established in the United States during the 1970s, 1980s, and 1990s developed outside of the traditional National Institutes of Health (NIH) and pharmaceutical company-sponsored research communities. Without doubt, practicing primary care physicians have contributed the most to the development of PBRNs. Their volunteer efforts and provision of practice facilities and staff has been the cornerstone of PBRNs from the beginning and continues today. However, PBRNs would not have evolved had it not been for the help of private foundations, professional societies and organizations, academic institutions, and both state and federal government.
The Rockefeller Foundation deserves recognition for seeding the enterprise, the Kellogg Foundation propelled networks to national scale, and presently, the Robert Wood Johnson Foundation is demonstrating the power of networking PBRNs to address critical national priorities. Numerous local and other national foundations have also played pivotal roles at pivotal moments. Had it not been for the support of the American Academy of Family Physicians, the American Academy of Pediatrics, the American Board of Family Medicine, the American College of Physicians, and other professional societies involving other medical specialties, nursing, and dentistry, PBRNs would not be poised as they are today for important work.

It is almost unheard of for PBRNs to not be working in collaboration with faculty of academic units, and many derive sustaining funding through the faithful management of thin research budgets by committed department chairs and residency program directors. There are examples of state government collaborations with PBRNs, such as in Oklahoma, Wisconsin, and North Carolina, that carry with them resources that otherwise would not be available for practice-based research.

At a federal level, the Health Resources and Services Administration, largely through its Title VII programs, has provided opportunities to compete for financial support that is widely credited with producing and sustaining effective PBRNs. The Bureau of Maternal and Child Health has been particularly important for PBRNs focused on children. Only one federal agency is designated by law to conduct primary care research, the Agency for Health Care Research and Quality (AHRQ). AHRQ, with critical leadership from John Eisenberg, Paul Nutting, and now Carolyn Clancy, Helen Burstin, David Lanier, and David Meyers, stepped up in the 1990s and lead the nation to fund and build capacity for practice-based research by creating specific PBRN programming. It would be difficult to overstate the importance of AHRQ in the maturation of practice-based research in the United States.

On occasion, various components of the NIH and the Centers for Disease Control have also enabled PBRNs and funded important research within them. Beginning in the early 1980s Curtis Hames, a member of the ASPN board of directors, visited yearly with Claude Lenfant, director of the National Heart Lung and Blood Institute, to dis- 
cuss the potential of PBRNs to improve research and health care. These conversations did not lead directly to PBRN funding, but planted an important seed. Dr. Lenfant understood the message, and on leaving the directorship of NHLBI in 2003, his editorial in $7 A M A$ focused on the need for translational research. But it was ultimately congressional pressure to translate the fruits of basic and clinical research into improved health of the United States population that is gradually forcing NIH to recognize the value of primary care research networks. ${ }^{33}$

Other important events that increased the visibility and importance of clinical research at NIH were the Graylin Clinical Research Conference in 1998 and the subsequent formation of the National Clinical Research Roundtable. ${ }^{34}$ The Roundtable published a widely cited report in $\mathcal{F} A M A$ in March of 2003 that mentioned the importance of PBRNs. ${ }^{35}$ The current interest in the NIH Roadmap initiative ${ }^{36}$ may result in even more important work in partnership with the nation's PBRNs; recent large grants to PBRNs in New Mexico, Michigan, and Minnesota to help develop a national electronic clinical trials and research network are encouraging. In addition, PBRN leaders are advising NIH on feasible ways to train a national clinical research workforce of 50,000 to 75,000 clinicians, of which half are likely to be primary care physicians.

\section{Conclusion}

In 1994, 28 PBRNs could be identified. In 2003, the AHRQ-funded PBRN Resource Center at the University of Indiana identified 111 PBRNs; 87 participated in a descriptive survey. These 87 PBRNs contained 2,724 practices in 44 states and Puerto Rico with 12,954 physicians (mean 152 per PBRN) caring for 14.7 million patients (mean 229,880 per PBRN). As of 2005, the Resource Center reports practices in PBRNs in all 50 states and Puerto Rico. These networks represent a precious national resource, poised to help cross the quality chasm and return to the public real health benefits for their investments in research. The current leadership and interest at NIH with major initiatives to enhance clinical research may have an enduring positive effect on primary care research in general, and specifically PBRNs, as research laboratories. The continuing leadership and support of AHRQ, major foundations, and academic units remain pillars on which PBRNs now rely.
The first chapter of PBRN history in the United States is completed, and these contemporary clinical research laboratories are probably about 5 years into their next phase. It is now known that primary care PBRNs are feasible and that they represent a useful infrastructure for scientific discoveries not otherwise possible. PBRNs, particularly those with enduring, core financial support and the ability to collaborate, have demonstrated a capacity to use multiple methods to answer very important questions that matter to millions of people. These networks are now both a place and a concept. As a place, they are laboratories for surveillance and research. As a concept, they express the still unmet need for practicing primary care clinicians to accept responsibility to improve frontline clinical care by understanding what is happening in their practices. Successes to date have been sufficient to incite the prestigious Institute of Medicine to recommend support to stabilize and expand practice-based primary care research networks. There is hard work ahead; work likely to transform frontline medical practice.

The current issue of the $7 A B F M$ represents another sort of milestone. This dedicated PBRN theme issue reports new research from PBRNs, and also captures some plenary addresses and special seminars presented at the 2005 AAFP Convocation of Practices in Colorado Springs. The articles selected demonstrate the breadth of primary care research and scholarship conducted by PBRNs. Overviews of major programs include an NIH Roadmap initiative (ePCRN), and the RE-AIM model for planning, evaluating, and reporting studies. Others report on methodologies pertinent to PBRNs: longitudinal research (OKPRN/Nijmegen); multimethod clinical trials (KAN); and strategies for population-based recruitment (CRN). Two studies examine processes related to medication prescribing: the OKPRN explored a best practices approach to prescription refills; and the ASIPS study determined the reasons pharmacies seek clarification of prescriptions ordered in primary care. Two surveys of physicians are included. The NRN reports on a national survey of approaches to lipid management, whereas the UNYNET presents a qualitative exploration of approaches to managing chronic renal disease. The MetroNet survey of patient use of the Internet for health information is an example of how large samples can be quickly achieved when multiple practices work as a team on 
data collection. Two networks (CaReNet and HPRN) collaborated on a medical record review to determine the nature of provider deferred decisions on $\mathrm{HbAlc}$ results. And from The Netherlands, the Nijmegen network reports on cardiovascular outcome prevention. In the history and evolution of PBRNs, these reports demonstrate that indeed, we have set sail.

\section{References}

1. Donaldson MS, Yordy KD, Lohr KN, Vanselow NA, editors. Primary care. America's health in a new era. Washington (DC): Institute of Medicine; National Academy Press; 1996.

2. American Academy of Family Physicians. Practicebased Research Networks in the 21 st Century-Proceedings from the 1998 conference convened by the AAFP Task Force to Enhance Family Practice Research. Available from: http://www.aafp.org/PreBuilt/ pbrnconfproc.pdf.

3. Mair A. Sir James MacKenzie, MD, 1853-1925: general practitioner. London: Royal College of General Practitioners; 1986.

4. Pemberton J. Will Pickles of Wensleydale: the life of a country doctor. Exeter: Royal College of General Practitioners; 1984.

5. Fry J. Common diseases: their nature, incidence, and care. Boston (MA): MTP Press; 1985.

6. Huygen FJA. Family medicine, the medical life history of families. New York (NY): Brunner Mazel; 1982.

7. Hames CG. Evans County cardiovascular and cerebrovascular epidemiologic study. Arch Intern Med 1971;128:883-6.

8. The National Influenza Surveillance Working Party. Canadian influenza surveillance first report: methods of the national recording system. Can Fam Physician 1977;23:64-72.

9. Froom J. An integrated medical record and data system for primary care. Part 1: The age-sex register definition of the patient population. J Fam Pract 1977;4:951-3.

10. Froom J. An integrated medical record and data system for primary care. Part 2: Classification of health problems for use by family physicians. J Fam Pract 1977;4:1149-51.

11. Froom J, Culpepper L, Boisseau V, et al. An integrated medical record and data system for primary care. Part 3: The diagnostic index manual and computer methods and applications. J Fam Pract 1977; 5:113-20.

12. Froom J, Culpepper L, Kirkwood R, Boisseau V, Mangone D. An integrated medical record and data system for primary care. Part 4: Family information. J Fam Pract 1977;5:265-70.

13. Farley ES Jr, Boisseau V, Froom J. An integrated medical record and data system for primary care. Part 5: Implications of filing family folders by area of residence. J Fam Pract 1977;5:427-32.

14. Froom J. An integrated medical record and data system for primary care. Part 6: A decade of problem-oriented medical records: a reassessment. J Fam Pract 1977;5:627-30.

15. Froom J, Kirkwood R, Culpepper L, Boisseau V. An integrated medical record and data system for primary care. Part 7: The encounter form: problems and prospects for a universal type. J Fam Pract 1977; 5:845-9.

16. Treat DF, Boisseau V. An integrated medical record and data system for primary care. Part 8: The individual patient's medical record. J Fam Pract 1977;5: 1007-15.

17. Marsland DM, Wood M, Mayo F. A databank for patient care, curriculum, and research in family practice: 526,196 patient problems. J Fam Pract 1976;3: 25-8, 37-68.

18. Mullner R, Byre C. Inventory of US health care databases, 1976-1983. American Hospital Association. US Department of Health and Human Services, Bureau of Health Professions, Office of Data Analysis and Management. Bethesda (MD): DHHS; 1985.

19. Perrin JM, Charney E, MacWhinney JB Jr., et al. Sulfisoxazole as chemoprophylaxis for recurrent otitis media: a double-blind crossover study in pediatric practice. N Engl J Med 1974;291:664-7.

20. Green LA, Simmons RL, Reed FM, et al. A family medicine information system: the beginning of a network for practicing and residency family physicians. J Fam Pract 1978;7:567-76.

21. Nelson EC, Kirk JW, Bise BW, et al. The cooperative information project, part 1: a sentinel practice network for service and research in primary care. J Fam Pract 1981;13(5):641-9.

22. Nelson EC, Kirk JW, Bise BW, et al. The cooperative information project. Part 2: Some initial clinical, quality assurance, and practice management studies. J Fam Pract 1981;13(6):867-76.

23. Becker LA, Iverson DC, Reed FM, Calonge BN, Miller RS, Freeman WL. A study of headache in North American primary care: a report from the Ambulatory Sentinel Practice Network. J Roy Coll Gen Practitioners 1987;37:400-3.

24. Becker LA, Iverson DC, Reed FM, Calonge BN, Miller RS, Freeman WL. Patients with new headache in primary care: a report from ASPN. J Fam Pract 1988;1:41-7.

25. Green LA, Becker LA, Freeman WL, Elliott E, Iverson DC, Reed FM. Spontaneous abortion in primary care: a report from ASPN. J Am Board Fam Pract 1988;1:15-23.

26. Freeman WL, Green LA, Becker LA. Pelvic inflammatory disease in primary care: a report from ASPN. Fam Med 1988;20:192-6. 
27. Culpepper L, Froom J. The International Primary Care Network: purpose, methods, and policies. Fam Med 1988;20:197-201.

28. Froom J, Culpepper L, Grob P, et al. Diagnosis and antibiotic treatment of acute otitis media: report from the International Primary Care Network. BMJ 1990;300:582-6.

29. Ornstein S, Jenkins RG, Nietert PJ, et al. A multimethod quality improvement intervention to improve preventive cardiovascular care: a cluster randomized trial. Ann Intern Med 2004;141:523-32. Summary for patients. Ann Intern Med. 2004;141: I53.

30. Feifer C, Ornstein SM. Strategies for increasing adherence to clinical guidelines and improving patient outcomes in small primary care practices. Jt Comm J Qual Saf 2004;30:432-41.

31. Niebauer L, Nutting PA. Primary care practice- based research networks active in North America. J Fam Pract 1994;38:425-6.

32. Hickner J. Practice-based primary care research networks. Primary care research: theory and methods. US Department of Health and Human Services. Public Health Service. Agency for Health Care Policy and Research. Rockville (MD): AHCPR; 1991.

33. Lenfant C. Claude Lenfant, MD: retiring NHLBI director looks ahead. Interviewed by Brian Vastag. JAMA 2003;290:1017-8

34. Report of the Graylin Consensus Development Conference. November 20-22, Graylin, NC. Washington (DC): Association of American Medical Colleges. November 1998.

35. Sung NS, Crowley WF Jr., Genel M, et al. Central challenges facing the national clinical research enterprise. JAMA 2003;289:1278-87.

36. Zerhouni E. The NIH roadmap. Science 2003;302: $63-72$. 